\title{
WestVirginiaUniversity
}

THE RESEARCH REPOSITORY @ WVU

Graduate Theses, Dissertations, and Problem Reports

2000

\section{Prenatal care utilization and its effect on pregnancy outcome in West Virginia}

Cortney Robyn Usakewicz

West Virginia University

Follow this and additional works at: https://researchrepository.wvu.edu/etd

\section{Recommended Citation}

Usakewicz, Cortney Robyn, "Prenatal care utilization and its effect on pregnancy outcome in West Virginia" (2000). Graduate Theses, Dissertations, and Problem Reports. 1064.

https://researchrepository.wvu.edu/etd/1064

This Thesis is protected by copyright and/or related rights. It has been brought to you by the The Research Repository @ WVU with permission from the rights-holder(s). You are free to use this Thesis in any way that is permitted by the copyright and related rights legislation that applies to your use. For other uses you must obtain permission from the rights-holder(s) directly, unless additional rights are indicated by a Creative Commons license in the record and/ or on the work itself. This Thesis has been accepted for inclusion in WVU Graduate Theses, Dissertations, and Problem Reports collection by an authorized administrator of The Research Repository @ WVU. For more information, please contact researchrepository@mail.wvu.edu. 
Prenatal Care Utilization and its Effect on Pregnancy Outcome in West Virginia

\author{
Cortney R. Usakewicz
}

Thesis Submitted to the College of Agriculture, Forestry, and Consumer Sciences

at

West Virginia University

in Partial Fulfillment of the Requirement for the degree of

Master of Science

In

Family and Consumer Sciences

M. Zafar A. Nomani, Ph.D., R.D., Chair

Hazel Hiza, Ph.D., R.D.

Barbara Warash, Ed.D.

Division of Family and Consumer Sciences

Morgantown, West Virginia

2000

Keywords: prenatal care utilization, pregnancy, WIC

Copyright 2000 Cortney R. Usakewicz 


\section{Abstract \\ Prenatal Care Utilization and its Effect on Pregnancy Outcome in West Virginia}

\section{Cortney R. Usakewicz}

The purpose of this study was to determine the impact of prenatal care utilization and maternal dietary intake on pregnancy outcome among West Virginia WIC participants. The sample size (102-155) used in this study varied, due to the number of subjects that provided complete information for specific variables. Data were obtained from survey questionnaires, participants' medical records and food frequency questionnaires. Data were analyzed by Statistica using Pearson's and Spearman's correlation.

Results of this study showed that women who experienced transportation problems or had problems with the father of the baby delayed initiation of prenatal care. In turn, these problems negatively affected gestation age and newborn weight of the infant. Alternatively, women who had family support and a good relationship with the father of their baby sought prenatal care earlier in their pregnancy. In addition, it was found that maternal nutrient intake was positively associated with newborn weight and length. Therefore, barriers and facilitators that impact on prenatal care utilization and ultimately on pregnancy outcome merit further research. 


\section{ACKNOWLEDGEMENTS}

I would like to express my graditute and thanks to the members of my thesis committee:

Dr. M. Zafar A. Nomani, advisor and chair, for his constant support, positive reinforcement and encouragement.

Dr. Barbara Warash, for her encouragement and for taking the time to serve on my committee.

Dr. Hazel Hiza, for allowing me the opportunity to work with her and for her valuable suggestions.

I would also like to thank my parents, Jeffrey and Nancy Usakewicz, for their continuous love and support and also for just being there for me any time throughout my educational career.

To everyone else who has helped me and been there for me along the way, Thanks. 


\section{Table of Contents}

Page

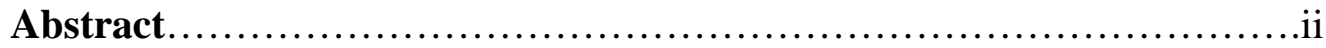

Acknowledgements................................................ii

List of Tables................................................... vi

Chapter I: Introduction..........................................1

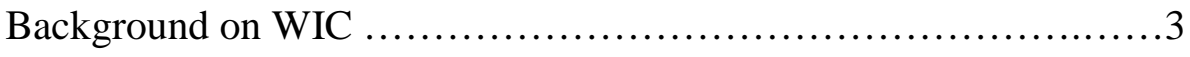

Statement of the Problem ........................................4

Objectives...............................................4

Limitations.................................................4

Chapter II: Review of Literature..................................6

Demographic Characteristics and Prenatal Care.....................8

Barriers Toward Prenatal Care.....................................10

Attitudes Toward Prenatal Care..................................13

Nutrient Intake and Pregnancy Outcome..........................16

Chapter III: Methodology ...................................... 18

Population and Sample.........................................18

Research Design..........................................19

Data Collection.......................................... 19

Analysis of Data..........................................22

Chapter IV: Results...........................................23

Trimester of Pregnancy......................................23

Initiation of Care ...........................................24 
Total Number of Prenatal Care Visits..........................24

Gestational Age............................................25

Maternal Complications......................................26

Newborn Complications.......................................27

Newborn Weight..........................................27

Newborn Length............................................28

Maternal Nutrient Intake........................................29

Maternal Nutrient Intake and Newborn Length...................30

Maternal Nutrient Intake and Newborn Weight.....................31

Chapter V: Discussion.......................................... 32

Chapter VI: Summary and Conclusion.............................37

References........................................................ 38

Appendices.................................................... 43

Appendix A: WIC Income Guidelines.........................44

Appendix B: Recommended Weight Gain during Pregnancy.......46

Appendix C: Recommended Dietary Allowances for Pregnancy.....48

Appendix D: Consent Forms..................................50

Vita............................................................ 57 


\section{List of Tables}

\section{Page}

Table 1: Distribution of Trimester...............................23

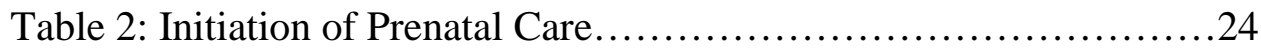

Table 3: Total Number of Prenatal Care Visits........................24

Table 4: Gestational Age.........................................25

Table 5: Maternal Complications.................................26

Table 6: Newborn Complications.................................27

Table 7: Newborn Weight.....................................27

Table 8: Newborn Length......................................28

Table 9: Maternal Nutrient Intake.................................29

Table 10: Maternal Nutrient Intake and Newborn Length...............30

Table 11: Maternal Nutrient Intake and Newborn Weight...............31 


\section{Chapter I}

\section{Introduction}

For nearly four decades, the effectiveness of prenatal care and pregnancy outcome has been a subject of serious debate. The demand for prenatal care is likely to be correlated with or indicative of pregnant women's behavior or health status. Therefore, women's self-selection behavior may be a major source of this debate. Prenatal care has long been endorsed to identify and in turn reduce the risks of preterm, low birth weight and other adverse pregnancy conditions (Liu, 1998). In addition, it appears that prenatal care is associated with increased length of gestation, which results in higher birth weights and better survival (Goldenberg, Patterson, \& Freese 1992). As a result, one of the United States governmental year 2000 objectives for pregnancy and infant health is the reduction in the percent of women who do not obtain prenatal care beginning in the first trimester (U.S. Government Printing Office, 1990). The Institute of Medicine (IOM) in 1988 defined prenatal care as follows:

"The diagnosis of pregnancy, the medical, educational, social and nutritional services needed to enhance the health and well being of the woman and fetus during pregnancy and the counseling and assistance required to plan for labor and delivery, postpartum, care for the mother and the pediatric care for the newborn."

Unfortunately, to date, there have been no set standard definitions of what adequate prenatal care is. However, the American College of Obstetricians and Gynecologists, (ACOG, 1989) recommends that prenatal care begin in the first trimester, continuing regularly every four weeks until 28 weeks, then every two weeks from 28 to 35 weeks, and weekly thereafter. When care is begun in the first trimester, between 12 and 14 visits 
are attended. In addition to the ACOG standards, methods used in past research to determine adequacy of prenatal care include frequency of visits, timing of visits (trimester started), and a combination of both (Stringer, 1998). Therefore, when referring to either standard to measure adequacy of prenatal care, circumstances related to mother's failure to obtain adequate prenatal care needs to be examined.

According to Goldenberg et al, (1992), the variables (circumstances) that were examined, which determine the initiation of prenatal care, fall into three general categories: demographic, situational and psychosocial. Age, race, marital status, maternal education and family income, which are considered demographic variables, have been related to determining the onset of seeking prenatal care. Situational circumstances, also known as external barriers, toward prenatal care such as transportation problems, employment status and financial restraints also determine the onset of seeking prenatal care. Finally, psychosocial circumstances such as attitudes about the pregnancy and encouragement from family members also affect the onset of prenatal care.

According to the US Department of Health and Human Services (1999), West Virginia ranks among one of the highest states in the country for the number of infant deaths per year. As a result, this may cause an increase in health care costs. One reason for infant mortality is the prevalence of low birth weight infants. Low birth weight is associated with and is related to the onset of prenatal care. This indicates that the earlier prenatal care is initiated, the risk of a low birth weight infant is decreased. Therefore, proper and early initiation of prenatal care is important for not only the better survival 
rates of infants in West Virginia but also to help reduce health care costs within the state (Baron, 1989).

\section{Background on WIC (Women, Infant and Children Program)}

WIC is the special supplemental nutrition program for women, infant, and children, up to five years of age, funded by the United States Department of Agriculture. The goal of WIC is to strive to improve the health of its participants. Pregnant women, postpartum women, breast feeding women, as well as infants and children up to 5 years are considered to be eligible (USDA, 1998). The participants/applicants must also meet USDA income standards as well as other eligibility criteria. For example, a gross annual income of $\$ 13,842$ for a household of one and no more than a gross annual income of $\$ 46,980$ for a household of eight (DHHR, 1995). Income guidelines for the WIC program in West Virginia are shown in appendix A. All participants must be seen at a WIC clinic before eligibility can be determined. Once eligibility has been established, all eligible participants receive food vouchers, which are used at WIC-approved stores. WIC provides monthly food vouchers that could be used to purchase milk, juice, cereal, eggs, cheese, peanut butter and dried beans, also, infant formula, juice and cereal are provided for the participants through WIC vouchers. Further, WIC provides nutrition counseling and education, breast feeding counseling and access to health care for eligible participants. This ensures that the participants as well as their children are receiving proper nutrition for their health and well being. Finally, the vouchers cover only the food items that are needed by each participant. This may vary from person to person depending on their individual nutritional needs (USDA, 1998). 


\section{Statement of the Problem}

Current research concerning the effectiveness of prenatal care and its impact on pregnancy outcome is controversial. Therefore, the purpose of this study was to determine how demographic characteristics, barriers and attitudes to prenatal care affect prenatal care utilization and their effect on complications at birth, gestational age and infant length and birth weight (pregnancy outcome). In addition, this study also sought to determine the effects of maternal dietary intake on pregnancy outcome. Specific focus was placed on West Virginian women, from Monongalia, Marion, Preston, Taylor and Harrison counties, who participated in the WIC program.

\section{Objectives of the Study}

1. To examine the effects of prenatal care utilization on pregnancy outcome among West Virginia WIC participants.

2. To determine the relationship between prenatal care utilization and pregnancy outcome.

3. To identify risk factors associated with lack of prenatal care among WIC participants in West Virginia.

\section{Limitations of the Study}

The participants for this study were chosen using purposive sampling. The goal of purposive sampling is to select cases or subjects that are likely to be information rich with respect to the purposes of the study (Gall, Borg, \& Gall, 1996). Therefore, the target population was specifically selected in regards to the purpose of this study. As a result, it is to be assumed that these women are a typical representation of women in these specific five counties. In addition, the sample size is relatively small. 
Lastly, another limitation of this study is that some of the information obtained from the participant's was self-reported. For example, the participant's prepregnancy weight as well as their dietary intakes/records. As a result, some of this information may not have been completely accurate and misleading. 


\section{Chapter II}

\section{Review of Literature}

Initiating prenatal care, is one of most important and best decision a woman can make while she is pregnant for both herself as well as her baby. It is during these visits that any medical or related problems can be found and treated. Also at these visits, nutritional status is assessed. Both nutritional assessment and counseling are integral components of prenatal care. It is recommended that average size women should gain between 25-35 pounds, while underweight and overweight women should gain between 35-40 pounds and 15-25 pounds, respectively. Recommendations for adequate weight gain during pregnancy are shown in appendix B. Inadequate or excessive weight gain could lead to an adverse pregnancy outcome (Kolasa \& Weismiller, 1997). Therefore, monitoring weight gain, which takes place at each prenatal visit, during pregnancy is important to help ensure the best pregnancy outcome.

In addition to monitoring weight gain, vitamin and mineral status is assessed at prenatal visits as well. Appendix C lists the 1989 recommended dietary allowances (RDA's) for women during pregnancy (Food \& Nutrition Board, 1989). According to Kolasa \& Weismiller (1997) a balanced diet that results in appropriate weight gain more than likely supplies adequate amounts of the vitamins and minerals required and needed during pregnancy. These nutrients should only be supplemented if they can not be met through the diet or if there is evidence of both benefit and lack of harmful effects. Vitamin $\mathrm{B}_{6}$, folate, vitamin $\mathrm{C}$, vitamin $\mathrm{D}$, iron, zinc and calcium are the common prenatal vitamins that are supplemented during pregnancy. Finally, women should receive counseling about a balanced diet, appropriate weight gain, and vitamin/mineral 
supplementation that is appropriate or inappropriate for them at their prenatal visits. Assessment and counseling should be ongoing throughout the entire pregnancy (Kolasa \& Weismiller, 1997). A good nutritional status during pregnancy is beneficial for both mother and baby and also results in fewer complications and in turn a better pregnancy outcome. Consequently, prenatal care is important for many reasons and should be sought early and continuously throughout pregnancy. However for various reasons, some women enter prenatal care late or fail to obtain prenatal care at all.

Generally, quantitative measures of prenatal care, as opposed to qualitative measures, are used for investigations and have focused on the timing of initiating care and the number of prenatal visits (Alexander \& Cornely, 1987). According to the Institute of Medicine (IOM, 1985), many women who receive inadequate prenatal care are those at greater than average risk of having a low birth weight infant. Further, the IOM indicated that low birth weight is a major determinant of infant morality. As mentioned earlier, the ACOG recommends that prenatal care begin in the first trimester and continue on a regular basis in order to receive the maximum amount of visits. By seeking early and continuous care, the prevalence of low birth weight infants will be reduced and in turn infant deaths associated with low birth weight will be decreased.

Most studies suggest that adequate prenatal care is an important determinant of having a good pregnancy outcome. Smith (1990) indicated that the lack of prenatal care is a major factor in poor obstetrical outcome. Smith also states that the number of infants born to women who receive inadequate prenatal care has increased.

A study done by Alexander \& Cornely (1987) found that higher birth weights and gestational ages were found among women who received adequate prenatal care. As a 
result of this finding, it is important for women to seek prenatal care early and continue to receive consistent care throughout their pregnancy in order to help improve birth weights and gestational ages of their infants.

Unfortunately, some women either wait too long to seek care or do not seek it at all. A study done by Elam-Evans and colleagues in 1995 found that for more than a decade the percentage of women who receive prenatal care after the first trimester has been around $24 \%$. Women who initiated prenatal care after the first trimester fall into three categories; those who initiate prenatal care in the second trimester, those who initiate prenatal care in the third trimester and those who receive no prenatal care. The latter two categories are usually combined and classified as late entry into prenatal care. Since late entry into prenatal care has been associated with more complications as well as adverse pregnancy outcomes, it is important to understand why these women delay care and intervene in order to promote earlier entrance into prenatal care.

\section{Demographic Characteristics and Prenatal Care}

Marital status, maternal education, socio-economic status, age and race will determine the onset of prenatal care. These demographic characteristics have been related to inadequate prenatal care (Goldenberg, et al., 1992). As a result, they will have a negative affect on prenatal care utilization, which in turn will affect pregnancy outcome.

Elam-Evans et al. (1995) found that women who received no prenatal care were more likely to be unmarried, have a higher parity (>4) and have shorter intervals between sequent births $(<24$ months) than women who received prenatal care in the third trimester. Consequently, these findings suggest that women with late entry into prenatal 
care are heterogeneous and that different intervention methods are needed in order to get these women into care or to seek care earlier. In addition, a study done by Amini, Catalano, and Mann (1996) also found similar results. They found that women who received little or no prenatal care were more likely to be young, unmarried, or adult women that already had several children.

Education usually has some effect on income. For example, level of education will either have a positive or negative effect and determine the amount of income one may have, which in turn may have an impact on prenatal care. A study done by Cooney (1985) found that level of income and education are related to each another and in turn will in fact affect the utilization of prenatal care. A higher education more than likely ensures a better job that pays more, which in turn affects the amount of income one may have. As a result, women with a higher education have better financial means of obtaining prenatal care than women with lower level of education. It was also found in this study that the highest rates of late entry or no prenatal care was observed among young, unmarried African Americans and Hispanics who have not completed high school.

In addition to Cooney's findings, the IOM (1988) found that the timing of prenatal visits correlates highly with educational attainment. The IOM stated that "the probability that pregnant women will obtain care late or not at all decreases steadily as her education level increases". Lastly, another study done by Melnikow and others in 1991 supported these findings. They also found that women with minimal or no prenatal care were likely to be less educated. As a result of receiving little or no care, lower birth 
weight infants as well as other adverse pregnancy outcomes (preterm infants) were increased.

Finally, age of the mother as well as their race may also influence the onset of prenatal care. Goldenberg et al. (1992) noted that the most consistent findings of delayed initiation of prenatal care were found among women who are less than 20 years of age. However, it has also been suggested that women older than 35 years have also shown poor utilization of prenatal care. As regards to race, findings suggest that black women have been associated with receiving less prenatal care than white women, however, it still remains unclear if race alone is a significant variable to measure the adequacy of prenatal care.

All of these demographic variables mentioned have an affect on determing the onset of prenatal care. Therefore, prenatal care utilization is usually affected in a negative way; the number of visits decrease and as a result, adverse pregnancy outcomes are increased. From these findings, it is important to recognize these variables as potential risk factors for poor prenatal care utilization and to implement a strategy for improving the onset of prenatal care. By doing this, the number of visits will increase which will improve pregnancy outcomes and in turn reduce hospital health care costs.

\section{Barriers Toward Prenatal Care}

Barriers, sometimes referred to as situational (internal) variables, are another factor that determine utilization of prenatal care. These barriers, to name a few, may include transportation problems, financial restraints (no insurance), and absence of childcare (Goldenberg et al., 1992). If a woman experiences any of these barriers, they 
may prevent her from seeking prenatal care and in turn have an adverse pregnancy outcome.

Transportation problems such as not having any means of getting to a clinic due to lack of transportation or having long travel times to get to clinics in order to obtain prenatal care may hinder women from receiving prenatal care. A study done by Joyce, et. al. (1984) found that women who do not seek prenatal care did not have transportation available to them. Melnikow and Alemango (1993) also supported these findings. They found that one of the primary reasons that women do not seek prenatal care was due to lack of transportation. Also, another study done by McDonald and Coburn (1988) found similar results. They found that travel time, among other things, was a significant predictor of when the onset of prenatal care begins.

Consequently, these findings suggest that if there are no forms or reliable forms of transportation available, or the commute to the clinic site was too far, a woman may not be motivated to seek prenatal care during her pregnancy. As a result, it is important for the health care provider to explain why prenatal care is important and encourage these women to seek care for the well being of themselves as well as their baby in order to prevent any adverse pregnancy outcomes.

Financial restraints such as the lack of insurance can prevent women from seeking prenatal care. Another reason, which may cause financial restraint, and may prevent women from seeking prenatal care, is taking time off from work. Meikle and colleagues in 1995 found that these particular financial restraints affected utilization of prenatal care by women who lacked insurance or would have to miss work for a prenatal care visit. These results indicated that the more financial restraints women had, the utilization of 
prenatal care decreased and the onset of care was delayed. Poland and others (1987) also found that women who received less prenatal care usually had no insurance. The results of this study indicated that having no insurance was significant in regards to prenatal care utilization. Therefore based on their results, they determined that having no insurance was the best predictor of the amount of prenatal care sought by these women. Although these women may be able to access health care through assistance, their financial restraints still remained a barrier for them to obtain care.

Women with other children may find it hard to obtain prenatal care for their current pregnancy. One reason for this may be due to absence of childcare. In 1971 Klein found that lack of a babysitter was an impediment to prenatal care. As a result, these women failed to obtain care during their pregnancy. In addition, O'Brien and Smith (1981) found that for women with other children, prenatal care may be problematic in terms of time and the inconvenience. This can also be associated with lack of child care because these women may not have any type of child care for their other children, which in turn makes them see prenatal care as too time consuming and inconvenient. Consequently, they are less likely to seek care.

Another study done by Joyce et al., (1984) also found similar results. They found that one reason women did not seek prenatal care was because they did not have childcare for their other children. York, Williams, \& Munro (1993) also supported these previous findings. They found that one of the more frequently cited reasons why women did not seek care early was because they had other small children at home. Similarly, Roberts, et al. (1998) found that women who had trouble finding childcare for their other 
children considered this a barrier to prenatal care and therefore, were more likely to enter care late if at all.

Many women, who do not seek prenatal care early or at all, may experience at least one of these barriers. It is important to realize that it is these barriers that prevent or deter women from seeking care and not because they do not want it or do not care about the health of their baby. If assistance were given to these women, they may be able to overcome these barriers and in turn prenatal care would be sought and less adverse pregnancy outcomes would result.

\section{Attitudes Toward Prenatal Care}

Attitudes, whether positive or negative, toward pregnancy will affect a woman's decision on obtaining prenatal care. When women wanted their pregnancy as well as have feelings of support and rewards from family and friends, healthy attitudes toward their pregnancy will result and will in turn affect the onset of care. On the other hand, negative attitudes such as an unwanted or unplanned pregnancy and having a delayed diagnosis of pregnancy will also affect the onset of care.

Support as well as rewards from friends and family tends to encourage women to seek prenatal care early in their pregnancy. Rewards, both personal and from family members such as "I want a healthy baby and my boyfriend or husband wants a healthy baby" respectively, will incite women to seek care. A study done by Schaffer \& LiaHoagberg (1994) found that these particular rewards (incentives) were very important to women in determining the onset of care. In addition, they indicated that having rewards and support from other family members and friends encouraged these women to obtain prenatal care. This is because they concluded that women tend to make choices about 
prenatal care within the context of their family life. Schaffer \& Lia-Hoagberg also found rewards from prenatal care visits such as receiving information and advice about their pregnancy as well as their primary care physician listening to them about their concerns also influence a women's decision about prenatal care.

A study done by McCormick and colleagues (1989) also published similar findings. They found that women who entered into care early were most likely receiving support from friends and family members and living with their boyfriends or husbands. This indicates that support and the influence of the male partner are a strong determinant for women in seeking prenatal care. Therefore, it is important to encourage women, who do not feel supported and feel deterred from seeking prenatal care. By encouraging these women, positive feelings and attitudes about their pregnancy will result and in turn will decrease the amount of time it takes for the initiation of prenatal care (O'Brien et al., 1981). In addition to increasing the utilization of prenatal care, better pregnancy outcomes will also result.

However, as mentioned previously, negative attitudes will also affect the utilization of prenatal care. How a woman feels about her pregnancy, if the pregnancy was unwanted or unplanned, is another factor that will determine the onset of care. According to Sable and others (1990), women with unplanned pregnancies were more than twice as likely to have had received inadequate care. This indicated that the utilization of prenatal care was delayed and, therefore, the number of prenatal visits was decreased for these women. Sable et al., (1990) also found that women that had received inadequate care during their pregnancy did not feel happy about it (did not want the pregnancy). Melnikow and Alemangno (1993) also found that not wanting the pregnancy 
was associated with receiving little or no prenatal care. Poland et al., (1987) also found similar trends among the onset of prenatal care. They found that initial attitudes about the pregnancy affected the onset of care. If the pregnancy was wanted or planned, the earlier prenatal care was sought, which in turn had an affect on the total number of prenatal care visits. Therefore, as a result, the more visits a woman has, the risks of an adverse pregnancy outcome decreased.

Unfortunately, many women do not know or realize they are pregnant for several months. As a result of a delayed diagnosis, the onset and amount of care is affected. In addition to the above findings, Sable et al., (1990) found that the strongest predictor of delayed onset of prenatal care was women not knowing that they were pregnant in the first four months of their pregnancy. When prenatal care is delayed until the second trimester, the adequacy of care is affected in a negative manner. This is a result of not only a later entry into care but also because this impacts the total number of visits a woman will attend. In order to avoid a delayed diagnosis of pregnancy, it is important for those women who think that they are pregnant to be encouraged not to hesitate confirming the pregnancy. By doing this, the utilization as well as the adequacy of prenatal care will improve, which in turn will lead to better pregnancy outcomes.

Women's attitudes regarding their pregnancy are a major determinant for prenatal care utilization. When a woman has a positive attitude toward her pregnancy the earlier prenatal care is sought. Consequently, it is important to understand that attitudes, positive or negative, are another factor, which may not be controllable, but affects the amount of care a woman receives throughout her pregnancy. 


\section{Nutrient Intake and Pregnancy Outcome}

Nutritional assessments and nutrition counseling are integral components of prenatal care. Maternal diet and nutritional status have been acknowledged to be important factors influencing fetal growth (Badart-Smook, and colleagues, 1997). In addition, nutritional status before as well as during pregnancy may have a profound effect on pregnancy outcome (Kolassa and Weismiller, 1997). Therefore, having a good nutritional status will not only benefit a woman during pregnancy but her baby as well. Consequently, better pregnancy outcomes will result.

Ceesay and others (1997) found that nutritional supplementation during pregnancy helped improve birth outcomes among a rural population. The supplement used in this study was high in energy and also contained protein, fat, calcium and iron. They found that taking this supplement was associated with an increased birth weight. However, it did not affect birth length because no significant association was seen.

A study done by Badart-Smook et al., (1997) found that maternal riboflavin intake was positively associated with birth weight and length. In their study, they found that an additional $1 \mathrm{mg}$ of riboflavin in the maternal diet was found to be associated with an increase in birth length of almost $1 \mathrm{~cm}$ and an increase in birth weight of about $149 \mathrm{gm}$. They concluded that since milk and milk products are high in riboflavin, that the consumption of these products during pregnancy should be encouraged.

Another study by Scholl and others (1996) found that a low folate intake was associated with a low birth weight infant. They found that a folate intake of only $60 \%$ of the RDA for pregnancy (400 micrograms) more than doubled the risk of bearing a low 
birth weight infant. Consequently, folate is not only beneficial in preventing neural tube defects but also in increasing infant birth weight.

A study by Goldenberg, Tamura, Neggers, Cooper, Johnston, DuBard, \& Hauth (1995) found an association between zinc supplementation and pregnancy outcome. It was found that women who received zinc supplementation during their pregnancy gave birth to infants with significantly larger birth weights than women who did not receive any supplementation. Therefore, they stated that inclusion of zinc in prenatal multivitamin/mineral tablets appears to be a reasonable strategy to help increase birth weight and in turn improve pregnancy outcome.

Overall, the total number of prenatal care visits are decreased when women enter care late or not at all. Consequently, these women may be jeopardizing the health of not only themselves but the health of their baby as well. Therefore, seeking prenatal care is an important step in helping to reduce complications associated with pregnancy. Also by seeking care, any adverse pregnancy outcomes will be decreased and in turn better pregnancy outcomes will result as well. The findings of the research studies presented in the review of literature, indicate multiple reasons why prenatal care may be sought late or not at all by some women and how this ultimately affects the utilization of prenatal care. 


\section{Chapter III}

\section{Methodology}

The purpose of this study was to determine how barriers and attitudes to prenatal care, affect prenatal care utilization and their effect on complications at birth, gestation age and weight and length of the infant. In addition, this study also sought to determine the effects of maternal dietary intake on pregnancy outcome. Specific focus was placed on West Virginia women who participated in the WIC program. In order to examine this, the following methodology was developed.

\section{Population and Sample}

The sampling design used in this study was purposive sampling. "In purposive sampling, the goal is to select cases that are likely to be information-rich with respect to the purposes of the study" (Gall, et al. 1996). All participants were required to sign an Informed Consent form, which has been previously approved by the West Virginia University of Institutional Review Board for Protection of Human Subjects. The Consent Form, Assent Form and Parental or Guardian Form are given in appendix D.

The target population was pregnant women either in their first, second, or third trimester term who were participants in the WIC program. WIC participants were selected because they are thought to best represent women of limited resources.

The total number of subjects interviewed was 156 . However, for the variables that were examined, in regards to prenatal care utilization and its effects on pregnancy outcome, the number of subjects that provided completed information ranged from 102 to 155. Recruitment of the sample/target population was obtained through cooperation from 
the government and local agencies that provide services for pregnant women with limited resources, i.e. WIC participants. As a result, the sample was not a random sample.

\section{Research Design}

A descriptive survey research design was used to collect data from pregnant women either in their first, second, or third trimester of pregnancy.

The purpose of a survey is to use questionnaires or interviews to collect data from participants in a sample about their characteristics, experiences and opinions in order to generalize the findings to a population that the sample is intended to represent (Gall et al., 1996).

The proposed study was carried out in four phases, with each successive phase building upon the previous one. Phase one involved the recruitment of subjects/participants;

recruitment, training and monitoring of staff; and baseline data collection. Phase two was an extension of phase one with continued recruitment of participants; training and monitoring of staff; data collection and refinement of data collection techniques; coding, data processing and analysis. Phase three involved data collection and refinement of data collection and coding, data analysis, and preliminary compilation of results. Phase four included a complete data analysis and final preparation of reports.

\section{Data Collection}

The data were collected via questionnaires. "Questionnaires and interviews are used extensively in educational research to collect information that is not directly observable. These data collection methods typically inquire about the feelings, motivations, attitudes, accomplishments and experiences of individuals" (Gall, et al. 1996). 
The questionnaires were previously pilot tested in order to determine the reliability and validity of their content. Subject's responses were numerically coded in order to analyze the data. This was done by assigning each variable/response a numerical number.

Information regarding infant characteristics and anthropometric data were obtained from the participant's medical record. In addition, the participant's nutrient and dietary intakes were obtained from their responses from the food frequency questionnaire (Block Dietary Systems, 1997). Finally, the following five questionnaires were also used in order to collect data on effects of prenatal care utilization and pregnancy outcome:

Questionnaire \#5 (personal information) provided the following information; age, race, martial status, income, education level, employment status, source of income (receiving any government assistance), and head of the household. Most of the information asked will be applied to both the mother and father of the infant. Race, martial status, educational level, and income were the specific demographic information taken into account and used for this study.

Questionnaire \#14 (Reproductive History) was used to obtain and collect data regarding any past pregnancies. Specifically for the purpose of this study, this questionnaire was used to obtain information about parity and whether this was the participants first pregnancy.

Questionnaire \#15 (prenatal care utilization) was used to collect data about prenatal care. Since the entire questionnaire seeks to obtain information about prenatal care utilization, all six questions were used to analyze the data. 
Questionnaire \# 17 (postnatal questionnaire) provided information regarding labor and delivery (after pregnancy). Question \# 6 was used to obtain data concerning maternal complications.

Questionnaire \# 18 (infant questionnaire) consisted of the following relevant variables regarding the infants: gestation age at birth (medical record), weight at birth (medical record), length at birth (medical record), and complications at birth (medical record).

The data were collected over a one-year period. As mentioned previously, the data were obtained through interviews using specific questionnaires to keep the interviews structured. The interviews, which were conducted by trained research assistants and took place either at the participant's homes, the local WIC agency, or on the West Virginia University campus depending on the subject's preference. During the first interview, the purposes of the study were discussed, consent and assent forms were signed, rapport was established and confidentiality was assured. Questionnaires regarding personal information, reproductive history and prenatal care utilization were administered to each subject during this time as well. In addition, a food frequency questionnaire was also administered and responses were analyzed using Block Dietary Systems (1997).

Like the first interview, the follow-up interview took place where the subject preferred. At the follow-up interview, postnatal and infant questionnaires were administrated (this information was also taken from the medical record). Finally, depending on the trimester the participant entered the study, they were paid for their time and involvement; $\$ 50$ for the first trimester and $\$ 35$ thereafter. 


\section{Analysis of Data}

This study sought to determine the effects of prenatal care utilization on pregnancy

outcome. In relation to the purpose of the study, infant gestational age along with weight and length of infant at birth and socio-economic characteristics were studied using descriptive statistics (frequencies, percentages, means, and medians). In addition, nutrient intakes were analyzed by frequency method (Block Dietary, 1997). The data were analyzed using Statistica for Windows, Version 5.5 (Sat Soft, 1999). Pearson's correlation was used when parametric variables were analyzed, while Spearman's correlation was used when non-parametric variables were analyzed. 


\section{Chapter IV}

\section{Results}

Factors that affect prenatal care utilization and pregnancy outcome are summarized.

\section{Trimester}

The trimester (I, II, or III) when each participant initiated prenatal care was taken into consideration. Table 1 lists the distribution of initiation of prenatal care by participants on trimester bases.

\section{Table 1. Distribution of participants by trimester upon initiating care}

\begin{tabular}{|lcc|}
\hline & Frequency & Percent \\
\hline First Trimester & 16 & $10 \%$ \\
Second Trimester & 65 & $41 \%$ \\
Third Trimester & 75 & $48 \%$ \\
\hline
\end{tabular}

Results show that more women in this study initiated care in the third trimester (48\%) versus first trimester $(10 \%)$ or second trimester $(41 \%)$. The gestation period $(n=111)$ of the subjects (mean \pm standard deviation) was 38.9 weeks \pm 3.1 . Twelve subjects had a gestation period of less than 36 weeks.

\section{Factors Associated with Initiation of Prenatal Care}

The factors associated with the initiation of prenatal care, whether first visit was initiated in first, second, or third trimester of pregnancy were examined. Table 2 shows what factors deter women from initiating prenatal care. It was found that having 
transportation and family problems as well as being unhappy about the pregnancy were significantly $(\mathrm{p}<0.05)$ negatively associated with initiating prenatal care. In other words, women experiencing these factors initiated prenatal care later than those women not experiencing these factors.

Table 2. Factors affecting initiation of prenatal care.

\begin{tabular}{|lllc|}
\hline Factor & $\mathrm{r}^{*}$ & $\mathrm{p}<$ & $\mathrm{n}$ \\
\hline $\begin{array}{l}\text { Transportation } \\
\text { Problems }\end{array}$ & -0.155 & 0.05 & 155 \\
Family Problems & -0.189 & 0.02 & 155 \\
$\begin{array}{l}\text { Unhappy about } \\
\text { Pregnancy }\end{array}$ & -0.164 & 0.05 & 155 \\
\hline
\end{tabular}

* Spearman's correlation coefficient

The participant's answered yes $=1$ or no $=2$ if transportation problems, family problems and/or being unhappy about the pregnancy deterred them from initiating prenatal care early.

\section{Total Number of Prenatal Care Visits}

The specific factor affecting the total number of prenatal care visits sought by participants are given in table 3 . The mean \pm the standard deviation for the total number of prenatal visits was; $12.4 \pm 3.3$.

Table 3. Factor affecting the total number of prenatal care visits.

\begin{tabular}{|llll|}
\hline Factor & $\mathrm{r}^{*}$ & $\mathrm{p}<$ & $\mathrm{n}$ \\
\hline Problems with the Father of the baby & 0.2 & 0.05 & 104 \\
\hline *Spearman's correlation coefficient & & & \\
\hline
\end{tabular}


Correlation revealed that participants experiencing problems with the father of the baby, Yes $=1, \mathrm{No}=2$, affected the total number of prenatal care visits sought. This indicated that if problems with the father of the baby did not exist, the total number of prenatal care visits were increased.

\section{Gestational Age}

The specific factors affecting gestational age are given in table 4.

Table 4. Factors associated with infant gestational age

\begin{tabular}{|lccc|}
\hline \multicolumn{1}{|c}{ Factor } & $\mathrm{r}$ & $\mathrm{P}<$ & $\mathrm{n}$ \\
\hline Transportation problems & $0.179^{*}$ & 0.06 & 111 \\
First pregnancy & $0.196^{* *}$ & 0.039 & 111 \\
Total number of prenatal care visits & $0.413^{* *}$ & 0.00 & 103 \\
Length of newborn & $0.361^{* *}$ & 0.00 & 109 \\
\hline
\end{tabular}

*Spearman's correlation coefficient

***earson's correlation coefficient

Spearman's correlation indicated that transportation problems $(\mathrm{yes}=1, \mathrm{no}=2)$ approached significance $(\mathrm{p}<0.06)$ and was positively associated with infant gestational age; that is subjects with transportation problems had a lesser gestational period than those subjects with no transportation problems. In addition, Pearson's correlation showed that a first time pregnancy $(\mathrm{yes}=1, \mathrm{no}=2)$ was significantly $(\mathrm{p}<0.05)$ positively associated with a decreased gestational age. Therefore, it was found that these factors were associated with a shortened gestational period and in turn a decreased gestation age. Further, according 
to Pearson's correlation, the total number of visits along with length of the newborn were also significantly $(\mathrm{p}<0.05)$ positively associated with gestational age of the infant. Maternal Complications

Table 5. The Factor associated with maternal complications.

\begin{tabular}{|llll|}
\hline \multicolumn{1}{|c}{ Factor } & During Pregnancy & \multicolumn{1}{c|}{ During Labor } & \multicolumn{1}{c|}{ During Delivery } \\
& & & \\
\hline Total number of & $\mathrm{r}=-0.222$ & $\mathrm{r}=-0.25$ & $\mathrm{r}=-0.18$ \\
prenatal visits & $\mathrm{p}<0.03$ & $\mathrm{p}<0.02$ & $\mathrm{p}<0.07$ \\
& $\mathrm{n}=102$ & $\mathrm{n}=102$ & $\mathrm{n}=102$ \\
\hline
\end{tabular}

Speraman's correlation indicated that complications during pregnancy were significantly $(\mathrm{p}<0.05)$ negatively associated with total number of prenatal visits. This indicated that participants who were experiencing complications while pregnant had more prenatal care visits. In addition, complications experienced during labor and delivery were also significantly $(\mathrm{p}<0.05)$ negatively associated with total number of prenatal care visits. Overall, more prenatal care visits were sought if there were more complications experienced by participants. Those who were experiencing complications during pregnancy also experienced complications during labor $(\mathrm{r}=0.2, \mathrm{p}<0.04)$ but was not associated with complications during delivery.

\section{Complications Experienced at Birth by the Newborn}

Results show (table 6) that the number of newborn complications at birth; such as apnea, sepsis, shock and/or seizures were significantly $(\mathrm{p}<0.05)$ negatively associated with gestational age and length of the newborn. 
Table 6. Factors associated with number of newborn complications **.

\begin{tabular}{|cccc|}
\hline \multicolumn{1}{|c}{ Factor } & $\mathrm{r}^{*}$ & $\mathrm{p}<$ & $\mathrm{n}$ \\
\hline Gestational age & -0.277 & 0.004 & 108 \\
\hline Length of Newborn & -0.214 & 0.026 & 108 \\
\hline
\end{tabular}

*Pearson's correlation coefficient

**apnea, sepsis, shock and/or seizures

\section{Newborn weight and length}

$\underline{\text { Newborn weight }}$

Table 7 lists the factors that affected the weight of the newborn at birth.

Table 7. Factors that affected the infants birth weight.

\begin{tabular}{|lccc|}
\hline \multicolumn{1}{|c}{ Factor } & $\mathrm{r}$ & $\mathrm{p}<$ & $\mathrm{n}$ \\
\hline $\begin{array}{l}\text { Transportation } \\
\text { Problems }\end{array}$ & $0.236^{*}$ & 0.02 & 111 \\
Family Problems & $0.177 *$ & 0.06 & 111 \\
$\begin{array}{l}\text { Total number of } \\
\text { visits }\end{array}$ & $0.207 * *$ & 0.04 & 103 \\
Length of newborn & $0.762 * *$ & 0.00 & 110 \\
Gestational age & $0.69 * *$ & 0.00 & 110 \\
\hline
\end{tabular}

*Spearman's correlation coefficient

**Pearson's correlation coefficient

Spearman correlation showed that transportation problems was significantly positively $(\mathrm{p}<0.05)$ associated with the newborn having a low birth weight, while family problems approached significance $(\mathrm{p}<0.06)$. In addition, Pearson correlation indicated 
that length of the newborn was also significantly $(\mathrm{p}<0.05)$ positively associated with an increased birth weight of the newborn: the longer the newborn measures at birth, the more the newborn will weigh at birth. Further, results showed that both gestational age along with the total number of visits also were significantly $(\mathrm{p}<0.05)$ positively associated with a higher birth weight of the newborn.

\section{$\underline{\text { Newborn Length }}$}

The factors that affect the length of the newborn at birth are listed in table 8 .

\section{Table 8. Factors that affect newborn length at birth.}

\begin{tabular}{|cccc|}
\hline Factor & $\mathrm{r}^{*}$ & $\mathrm{p}<$ & $\mathrm{n}$ \\
\hline First Pregnancy & 0.251 & 0.008 & 111 \\
Gestational Age & 0.568 & 0.000 & 110 \\
\hline
\end{tabular}

*Pearson's correlation coefficient

Correlation showed that both a first time pregnancy and a decreased gestational age contributed $(\mathrm{p}<0.05)$ to a shorter length of the newborn.

\section{The association of maternal nutrient intake on pregnancy outcome}

Table 9 shows the participant's $(n=153)$ energy and nutrient intake (mean \pm standard deviation). 
Table 9. Participants nutrient intake (mean \pm standard deviation)

\begin{tabular}{|c|c|c|}
\hline Nutrient & Mean & \pm Standard Deviation \\
\hline Energy (Kcal) & 2441 & \pm 810.0 \\
\hline Protein $(\mathrm{gm})$ & 96 & \pm 36.4 \\
\hline Fat (gm) & 93.3 & \pm 39.2 \\
\hline Carbohydrate (gm) & 306.3 & \pm 100.0 \\
\hline Carbohydrate (\%) & 51 & \pm 6.8 \\
\hline Protein (\%) & 15.7 & \pm 2.8 \\
\hline Fat (\%) & 34 & \pm 6.1 \\
\hline Calcium (mg) & 1379 & \pm 616.0 \\
\hline Phosphorous (mg) & 1700 & \pm 642.2 \\
\hline Iron $(\mathrm{mg})$ & 16 & \pm 6.0 \\
\hline Folate (mg) & 420 & \pm 169.3 \\
\hline Sodium (mg) & 3584 & \pm 1320.3 \\
\hline Potassium (mg) & 3552 & \pm 1220.0 \\
\hline Magnesium (micrograms) & 326 & \pm 117.0 \\
\hline Zinc (mg) & 13.4 & \pm 5.3 \\
\hline Vitamin $B_{1}(\mathrm{mg})$ & 1.9 & \pm 0.64 \\
\hline Vitamin $\mathrm{B}_{2}(\mathrm{mg})$ & 2.9 & \pm 1.13 \\
\hline Vitamin $B_{3}(m g)$ & 23 & \pm 8.9 \\
\hline Vitamin $\mathrm{B}_{6}(\mathrm{mg})$ & 2.1 & \pm 0.80 \\
\hline Vitamin C (mg) & 133.6 & \pm 71.0 \\
\hline Vitamin A (IU) & 7911 & \pm 3810.0 \\
\hline Vitamin E ( $\propto-T E)$ & 11 & \pm 5.0 \\
\hline
\end{tabular}


In this study, there were significant associations between energy, macronutrient intake (carbohydrate, protein and fat) and micronutrient intake and the length and weight of the newborn. Table 10 shows the association between maternal nutrient intake and newborn length, $\mathrm{n}=109$.

Table 10. The association of maternal nutrient intake on newborn length

\begin{tabular}{|c|c|c|}
\hline Nutrient & $\mathrm{r}$ & $\mathrm{p}<$ \\
\hline Energy (Kcal) & 0.261 & 0.006 \\
\hline Protein $(\mathrm{gm})$ & 0.225 & 0.019 \\
\hline Fat (gm) & 0.203 & 0.034 \\
\hline Carbohydrate (gm) & 0.255 & 0.008 \\
\hline Iron $(\mathrm{mg})$ & 0.34 & 0.000 \\
\hline Vitamin A (IU) & 0.255 & 0.008 \\
\hline Vitamin $E(\propto-T E)$ & 0.252 & 0.008 \\
\hline Vitamin $B_{1}(\mathrm{mg})$ & 0.319 & 0.001 \\
\hline Vitamin $B_{2}(m g)$ & 0.213 & 0.026 \\
\hline Vitamin $B_{3}(m g)$ & 0.353 & 0.000 \\
\hline Vitamin $B_{6}(\mathrm{mg})$ & 0.291 & 0.002 \\
\hline Vitamin C (mg) & 0.262 & 0.006 \\
\hline Folate $(\mathrm{mg})$ & 0.314 & 0.001 \\
\hline Zinc (mg) & 0.284 & 0.003 \\
\hline Sodium (mg) & 0.236 & 0.013 \\
\hline Potassium (mg) & 0.301 & 0.016 \\
\hline
\end{tabular}


Results showed that newborn length was positively associated with the above nutrients. This indicated the higher the intake of these specific nutrients, the length of the newborn was increased. Table 11 shows the association between maternal nutrient intake and newborn weight, $\mathrm{n}=109$.

Table 11. The association of maternal nutrient intake on newborn weight

\begin{tabular}{|l|c|c|}
\hline \multicolumn{1}{|c|}{ Nutrient } & $\mathrm{r}$ & $\mathrm{p}<$ \\
\hline Energy (Kcal) & 0.247 & 0.010 \\
\hline Fat $(\mathrm{gm})$ & 0.231 & 0.016 \\
\hline Carbohydrate (gm) & 0.227 & 0.018 \\
\hline Iron (mg) & 0.268 & 0.005 \\
\hline Vitamin $\mathrm{B}_{1}(\mathrm{mg})$ & 0.264 & 0.005 \\
\hline Vitamin $\mathrm{B}_{3}(\mathrm{mg})$ & 0.316 & 0.001 \\
\hline Vitamin $\mathrm{B}_{6}(\mathrm{mg})$ & 0.286 & 0.003 \\
\hline Vitamin C (mg) & 0.223 & 0.020 \\
\hline Folate (mg) & 0.236 & 0.013 \\
\hline Vitamin E ( $\propto-\mathrm{TE})$ & 0.245 & 0.009 \\
\hline Zinc $(\mathrm{mg})$ & 0.241 & 0.012 \\
\hline Potassium $(\mathrm{mg})$ & 0.211 & 0.028 \\
\hline
\end{tabular}

Results indicated that the above nutrients were positively associated with increased newborn weight. Therefore, the higher the intake of these nutrients, the more the newborn weighed at birth. 


\section{Chapter V}

\section{Discussion}

In the present study, demographic characteristics such as age, income, education level, martial status and race were not found to be associated with prenatal care utilization and pregnancy outcome. This may be due to the small sample size and the participant's having similar backgrounds (i.e. WIC participants). The factors, which were found to have a significant impact on prenatal care utilization and pregnancy outcome, are discussed below.

\section{Initiation of Prenatal Care}

The time prenatal care is initiated (whether in the first, second or third trimester) is associated with specific maternal barriers and attitudes. The majority of the subjects (48\%) initiated care in the third trimester. Analysis of barriers and attitudes that deterred women from initiating care early were having transportation problems, having family problems and being unhappy about the pregnancy. These findings were in agreement with the following previous findings.

Results from Joyce et al. (1984) and Melnikow et al. (1993) also found that women who experienced transportation problems, such as lack of transportation, initiated care later compared to women who had transportation available to them. Sable et al. (1990) found that being unhappy about the pregnancy was also associated with inadequate (late initiation) prenatal care. York et al. (1993) found that lack of family support, which is indicative of having family problems, was associated with women initiating care late in the pregnancy. 


\section{Total number of prenatal visits}

The mean number of prenatal care visits sought by participants was $12.4 \pm 3.3$ visits. Analysis of factors that affected the number of prenatal visits found only one factor to be significant. Having problems with the father of the baby was significantly associated with a decreased number of prenatal care visits.

McCormick et al. (1989) supported this finding. They also found that when a stable relationship with a man, such as living with their husband or boyfriend (father of the baby) was lacking and therefore, problems with the father of the baby existed, the total number of prenatal care visits were affected. It was found that these women had fewer visits compared to women who did not experience problems with the father of the baby.

\section{Gestational Age}

Gestational age was associated with transportation problems, a first pregnancy, total number of prenatal care visits and birth length. These results were supported by several previous studies regarding gestational age. As mentioned earlier, transportation problems are associated with delayed initiation of prenatal care. This in turn affects the total number of prenatal care visits women may seek. Therefore, in this case, transportation problems and total number of prenatal care visits can be considered one entity, with one effecting the other, and together both affecting gestational age. Alexander et al. (1987) found that more prenatal care was associated with less prematurity (increased gestational age). Amini et al. (1996) also found that women with fewer prenatal care visits delivered early and therefore, the gestational age of the newborn was negatively affected. 
Prysak, Lorenz, and Kisly (1995) showed that being older (> 35) and nulliparous (first pregnancy) was associated with preterm birth, which is indicative of having a decreased gestational age. As previously mentioned, the results of this study did not show that being older had any significant impact on prenatal care utilization and pregnancy outcome. However, the results did show that being nulliparous was associated with decreased gestational age. Finally, in regards to birth length, Cole et al. (1997) found a clear trend that associated infants with increased birth weights and lengths with an increased gestational age.

\section{Maternal complications}

Results showed that more prenatal care visits were attended if the participant was experiencing any complications related to the pregnancy. These results regarding maternal complications and total number of prenatal care visits are similar to the findings of Blondel and others (1993). They found that women who experienced complications or illness while pregnant were more likely to obtain prenatal care and consequently have

more prenatal care visits compared to women who were healthy. Alexander et al., (1987) also found that women who reported experiencing complications during their pregnancy had more prenatal care visits.

\section{Newborn complications}

It was found that the number of complications experienced by the newborn at birth was associated with gestational age and birth length of the newborn. Smith (1990) found that preterm labor, which is associated with a decreased gestational age, carries a two to three times greater risk of a baby born not only with a low birth weight but also with having increased complications at birth. 


\section{Newborn Weight and Length}

Results of this study showed that several factors such as transportation problems, family problems, total number of prenatal visits, birth length and gestational age affected newborn weight. As stated previously, transportation problems along with family problems were found to deter women from seeking prenatal care and in turn will affect the total number of prenatal care visits sought by these women. Joyce et al. (1984) and Melnikow and Alemagno (1993) supported results regarding transportation problems, while McCormick et al. (1989) and York et al. (1993) supported results regarding family problems (lack of family support).

Blondel et al. (1993) found women without prenatal care were observed to have a higher risk of having a low birth weight infant. Alexander et al. (1987) showed that women not receiving any prenatal care had the most disadvantageous pregnancy outcomes. However, pregnancy outcomes were found to improve with increased use of prenatal care. Therefore, the more prenatal visits sought the risk of having a low birth weight infant will decrease.

Results regarding gestational age being associated with newborn weight were supported by both Leveno, Cunningham, Roark, Nelson, and Williams (1985) and Williams and O'Brien (1997). Leveno and associates found that preterm labor, which is indicative of decreased gestational age, was associated with delivery of a low birth weight infant. In Williams's study, they found that birth weight was significantly associated with gestational age.

Upon analysis it was found that a first pregnancy and gestational age were associated with shorter newborn length. As mentioned previously, Cole et al. (1997) 
found that increased birth weight along with birth length was associated with increased gestational age.

\section{Maternal Nutrient Intake and Pregnancy Outcome}

Analysis of maternal nutrient intake of the participants and its association with pregnancy outcome found that energy, macronutrient and micronutrient intake were associated with improved pregnancy outcome. This may be due to the adequate intake of these nutrients and diet counseling the participant's received from the WIC program. These findings are supported in part by Ceesay et al., 1997. They also found that energy, protein, fat and iron were associated with increased birth weight.

Results from both Goldenberg et al. (1995) and Scholl et al. (1996) also showed that micronutrient intake was associated with improved pregnancy outcome (birth weight). Goldenberg found that supplementation of zinc increased birth weight and consequently improved pregnancy outcomes. Scholl and colleagues showed that a low folate intake was associated with an increased risk of a low birth weight infant. Therefore, folate intake has an effect on pregnancy outcome with a higher intake being associated with an improved pregnancy outcome.

The results regarding vitamin $\mathrm{B}_{2}$ (riboflavin) intake are similar to the findings of Badart-Smook et al., 1997. The results of their study also found that riboflavin was associated with improved pregnancy outcomes. They found that riboflavin was associated with increased birth length as well as birth weight. 


\section{Chapter VI}

\section{Summary and Conclusion}

Results showed that the majority of the participants (48\%) entered prenatal care in the third trimester and the average number of prenatal care visits was $12.4 \pm 3.3$. Further, the results of this study found that having transportation problems along with problems with the father of the baby significantly affected utilization of prenatal care and pregnancy outcome.

Maternal nutrient intake was also found to be associated with pregnancy outcome. Energy intake, macronutrient intake, along with micronutrient intake were found to have an impact on pregnancy outcome. It was found that there was a positive association between energy, macronutrient and micronutrient intake and pregnancy outcome.

In order to have a healthy baby, it is very important that prenatal care is sought early and continuously throughout the pregnancy and that women at risk for late initiation be encouraged to obtain prenatal care early. Finally, transportation and family problems need to be resolved for improved implementation of prenatal care.

\section{Recommendations}

Results of this research will stimulate other researchers along with government officials and medical professionals to pursue aggressive interventions to help resolve problems that contribute to preventing women from seeking prenatal care. For example, making transportation more accessible for these women through government or public funding. In addition, both education and support needs to be provided and given to these women in regards to the importance of prenatal care. 


\section{References}

ACOG. American College of Obstetricians and Gynecologists. Standards for obstetric and gynecological services. $7^{\text {th }}$ ed. Washington, D.C: ACOG; 1989.

Alexander, G. R., \& Cornely, D. A. (1987). Prenatal care utilization: Its measurement and relationship to pregnancy outcome. American Journal of Preventive Medicine, 3, 243-254.

Amini, S.B, Catalano, P.M., \& Mann, L. I. (1996). Effect of prenatal care on obstetrical outcome. The Journal of Maternal-Fetal Medicine, 5, 142-150.

Badard-Smook, A., Adriana, C., Houwelingen, V., Monique, Al., Kester, A.D.M., Hornstra, G. (1997). Fetal growth is associated positively with maternal intake of riboflavin and negatively with maternal intake of linoleic acid. Journal of the American Dietetic Association, 97, 867-870.

Baron, R.C., Bailey C.W., \& Thoenen E.G. (1989). Infant mortality in West Virginia: Identifying risk factors for public health interventions. The West Virginia Medical Journal, 85, 489-495.

Block Dietary Systems. Berkeley, CA. 1997.

Blondel, B., Dutilh, P., Delour, M., \& Uzan, S. (1993). Poor antenatal care and pregnancy outcome. European Journal of Obstetrics and Gynecology and Reproductive Biology, 50, 191-196. 
Ceesay, S.M., Prentice, A.M., Cole, T.J. Foord, F., Weaver, L.T., Poskitt, E.M., \& Whitehead, R.G. (1997). Effects on birth weight and perinatal mortality of maternal dietary supplements in rural Gambia: 5 year randomized controlled trial. British Medical Journal, 315, 786-790.

Cole, T. J., Henson, G. L., Tremble, J. M., \& Colley, N. V. (1997). Birthweight for length: Ponderal index, body mass, or Benn index? Annuals of Human Biology, 24, 289-298.

Cooney, J. P. (1985). What determines the start of prenatal care? Medical Care, 23, 986-997.

Department of Health and Human Resources; Bureau for Public Health. (1995). Tomorrow's dreams start with WIC Today! Charleston, WV [Brochure]. Elam-Evans, L. D., Adams, M. M., Gargiullo, P. M., Kiely, J. L. (1995). Heterogeneity between women who received prenatal care in the third trimester and those who received no prenatal care. Journal of the American Medical Women's Association, 5, 175-177.

Food and Nutrition Board National Academy of Sciences. (1989). Recommended Dietary Allowances. 10 ed; Washington, D.C.

Gall, M.D., Borg, W.R., \& Gall, J.P. (1996). Education research: An introduction. White Plans, N.Y.: Longman Publishers USA.

Goldenberg, R. L., Patterson, E. T., Freese, M. P. (1992). Maternal demographic, situational and psychosocial factors and their relationship to enrollment in prenatal care: A review of the literature. Women and Health, 19, 133-151. 
Goldenberg, R.L., Tamura, T., Neggers, Y., Cooper, R.L., Johnston, K.E., DuBard, M.B., \& Hauth, J.C. (1995). The effect of zinc supplementation on pregnancy outcome. Journal of the American Medical Association, 274, 463-468.

Institute of Medicine National Academy of Sciences. (1988). Prenatal Care: Reaching mothers, reaching infants. Washington, D.C. Institute of Medicine National Academy of Sciences. (1990). Nutrition During Pregnancy. Washington, D.C.

Institute of Medicine National Academy of Sciences. (1985). Preventing Low Birthweight. Washington, D.C.

Joyce, K., Diffenbacher, G., Greene, J., \& Sorokin, Y. (1984). Internal and external barriers to obtaining prenatal care. Social Work in Health Care, 9, 89-96.

Klein, L. (1971). Nonregistered obstetric patients. American Journal of Obstetrics and Gynecology, 110, 795-802.

Kolasa, K. M. \& Weismiller, D. G. (1997). Nutrition during pregnancy. American Family Physician, 56, 205-212.

Kramer M. S. (1993). Effects of energy and protein intakes on pregnancy outcome: An overview of the research evidence from controlled clinical trials. American Journal of Clinical Nutrition, 58, 627-635.

Leveno, K. J., Cunningham, G., Roark, M. L., Nelson, S. D., \& Williams, L. (1985). Prenatal care and the low birth weight infant. Journal of the American College of Obstetricians and Gynecologists, 66, 599-605.

Liu, G. G. (1998). Birth outcomes and the effectiveness of prenatal care. Health Services Research, 32, 805-823. 
McCormick, M. C., Brooks-Gunn, J. Shorter, T., Holmes, J. H., Wallace, C. Y., \& Heagarty, M. C. (1989). Outreach as Case Finding: Its effect of enrollment in prenatal care. Medical Care, 27, 103-111.

McDonald, T. P. \& Coburn, A. F. (1988). Predictors of Prenatal care utilization. Social Science in Medicine, 27, 167-171.

Meikle, S. F., Orleans, M., Leff, M., Shain, R. \& Gibbs, R. S. (1995). Women's reasons for not seeking prenatal care: Racial and ethnic factors. Birth, 22, 81-86.

Melnikow, J. \& Alemagno, S. (1993). Adequacy of prenatal care among inner-city women. The Journal of Family Practice, 37, 575-582.

Melnikow, J., Alemagno, S., Rottman, C. \& Zyanski, S. J. (1991). Characteristics of inner-city women giving birth with little or no prenatal care: A case -control study. The Journal of Family Practice, 32, 283-288.

O’Brien, M. \& Smith, C. (1981). Women's views and experiences of antenatal care. The Practitioner, 225, 123-125.

Poland, M. L., Ager, J. W., \& Olson, J. M. (1987). Barriers to receiving adequate prenatal care. American Journal Obstetrics and Gynecology, 157, 297-303.

Prysak, M., Lorenz, R. P., \& Kisly, A. (1995). Pregnancy outcome in nulliparous women 35 years and older. Obstetrics and Gynecology, 85, 65-70.

Roberts, R. O., Yawn, B. P., Wickes, S. L., Field, C. S., Garretson, M., \& Jacobsen, S. J. (1998). Barriers to prenatal care: Factors associated with late initiation of care in a middle class Midwestern community. The Journal of Family Practice, 4, 53-61. 
Sable, M. R., Stockbauer, J. W., Schramm, W. F., \& Land, G. H. (1990). Differentiating the barriers to adequate prenatal care in Missouri, 1987-88. Public Health Reports, 105, 549-555.

Sat Soft 5.5 [Computer software]. (1999). Tulsa, OK: Statistica.

Schaffer, M. A. \& Lis-Hoagberg, B. (1994). Prenatal care among low-income women. Families in Society, 152-159.

Scholl, T.O., Hediger, M.L., Schall, J.I., Khoo, C.S., \& Fischer, R.L. (1996). Dietary and serum folate: Their influence on the outcome of pregnancy. American Journal of Clinical Nutrition, 63, 520-525.

Smith, R. E. (1990). Infant mortality and prenatal care. Henry Ford Hospital Medical Journal, 38, 137-139.

Stringer, M. (1998). Issues in determining and measuring adequacy of prenatal care. Journal of Perinatology, 18, 68-73.

U.S. Government Printing Office. (1990). Healthy people 2000: National health promotion and disease prevention objectives. Washington, D.C.

United States Department of Agriculture. (1998). A healthy start. Alexandria, VA. United States Department of Health and Human Services. (1999). Health, United States, 1999; With Health and Aging Chartbook. Hyattsville, MD.

Williams M. C. \& O’Brien W. F. (1997). A comparison of birth weight and weight/length ratio for gestation as correlates of perinatal morbidity. Journal of Perinatology, 5, 346-350.

York, R., Williams, P., \& Munro, B. H. (1993). Maternal factors that influence inadequate prenatal care. Public Health, 10, 241-244. 


\section{Appendices}


Appendix A 


\section{WIC INCOME GUIDELINES}

$\begin{array}{cccc}\text { Size of Household } & \begin{array}{c}\text { Gross Income } \\ \text { Weekly }\end{array} & \begin{array}{c}\text { Gross Income } \\ \text { Monthly }\end{array} & \begin{array}{c}\text { Gross Income } \\ \text { Yearly }\end{array} \\ 1 & \$ 287 & \$ 1,242 & \$ 14,893 \\ 2 & \$ 387 & \$ 1,673 & \$ 20,073 \\ 3 & \$ 486 & \$ 2,105 & 25,253 \\ 4 & \$ 586 & \$ 2,537 & \$ 30,433 \\ \text { For each additional family } & +\$ 100 & +\$ 432 & +\$ 5,180 \\ \text { member add: } & & & \end{array}$

Adapted from The United States Department of Agriculture, 1998. 
Appendix B 
Weight Gain Recommendations for Pregnancy

\section{$\%$ of Standard (Prepregnancy Weight) Weight Gain Goal/Recommendation}

$\begin{array}{cr}<90 \% \text { of Standard } & 28-40 \mathrm{lbs} . \\ \text { Standard } & 25-35 \mathrm{lbs} . \\ >129 \% \text { of Standard } & 15-25 \mathrm{lbs} . \\ >135 \% \text { of Standard } & \text { At least } 5 \mathrm{lbs} .\end{array}$

Adapted from Institute of Medicine, National Academy of Sciences (1990). Nutrition

During Pregnancy. National Academy Press, Washington, D.C. 
Appendix C 


\section{Recommended Dietary Allowances (RDA) During Pregnancy}

\begin{tabular}{|c|c|}
\hline Nutrient & RDA \\
\hline Protein $(\mathrm{g})$ & 60 \\
\hline Vitamin A (vg RE) & 800 \\
\hline Vitamin D (vg) & 10 \\
\hline Vitamin $E(m g \alpha-T E)$ & 12 \\
\hline Vitamin C (mg) & 70 \\
\hline Folic Acid (vg) & 400 \\
\hline Thiamin (mg) & 1.5 \\
\hline Riboflavin (mg) & 1.6 \\
\hline Niacin (mg NE) & 17 \\
\hline Vitamin $\mathrm{B}_{6}(\mathrm{mg})$ & 2.2 \\
\hline Vitamin $B_{12}(v g)$ & 2.2 \\
\hline Calcium(mg) & 1,200 \\
\hline Iron (mg) & 30 \\
\hline Phosphorous (mg) & 1,200 \\
\hline Magnesium (mg) & 300 \\
\hline Zinc (mg) & 15 \\
\hline
\end{tabular}

Adapted from Food and Nutrition Board, National Academy of Sciences. Recommended Dietary Allowances, ed. 10, Washington, DC, 1989, National Academy Press. 
Appendix D 
Division of Family and Consumer Sciences

West Virginia University

College of Agriculture, Forestry and Consumer Sciences

\title{
Assent Form
}

\author{
Factors Affecting Perinatal, Maternal, \\ Nutritional Status, Healthcare and pregnancy Outcomes
}

Introduction. I have been asked to be in this research study, which has been explained to me by , a research assistant on this project. This study is funded by the United States Department of Agriculture (USDA) and the West Virginia Agriculture and Forestry Experiment Stations, West Virginia University, College of Agriculture, Forestry and Consumer Sciences.

Purpose(s) of the study. I have been told that the purpose of this study is to learn more about the many factors that may have an impact on my baby's health.

Description of Procedure. This study will be performed in my home or at the WIC site. I will meet privately with the research assistant. I will be interviewed to answer several lists of written questions. The questions will be related to how I eat during pregnancy, my food shopping practices, my maternal health, prenatal care, and a variety of questions that could have a positive or negative impact on my baby's health. I will also be asked to take one blood test by a trained lab technician to determine the level of certain nutrients in my blood. The quantity of blood to be taken from me for the one time blood draw will be about one tablespoon. Additionally, I will be asked to provide all of the information from my prenatal records or my baby's birth certificate or take a blood test. I understand that it will take me about two hours to answer the interview questions and about ten minutes for the blood test. I will be given the opportunity to view the questionnaires before signing the consent forms.

Risks. I understand that what they learn from this study may help pregnant women and infants in West Virginia and other states.

Financial Considerations. If I join the study during my last trimester of pregnancy I understand that I will receive $\$ 35$ in cash after I complete the study. If I join the study when I am in my first or second trimester of pregnancy I will receive \$50 in cash after I complete the study. 
Division of Family and Consumer Sciences

West Virginia University

College of Agriculture, Forestry and Consumer Sciences

Confidentiality. I understand that any information obtained as a result of my participation in this research will be kept as legally possible. I understand that these research records will just like hospital records, may be subpoenaed by court order or may be inspected by federal regulatory authorities. However, I also know that such an occurrence is highly unlikely given the nature of this research. If any publications result from this research, neither my name nor any information from which I might be identified will be published.

Voluntary Participation. Participation in this study is voluntary. I understand that I may withdraw from this study at any time. Refusal to participate or withdraw will involve no penalty or loss of medical benefits or negative consequences for me. I have been given the opportunity to ask questions about the research, and I have received answers concerning areas I do not understand. Upon signing this form, I will receive a copy.

I willing consent to participate in this study.

Signature of Parent or Guardian

Signature of Investigator or

Investigator's Representative
Date

Date 
Division of Family and Consumer Sciences

West Virginia University

College of Agriculture, Forestry and Consumer Sciences

\title{
CONSENT FORM
}

\author{
Factors Affecting Perinatal, Maternal, \\ Nutritional Status, Healthcare and Pregnancy Outcomes
}

Introduction. I have been asked to be in this research study, which had been explained to me by a research assistant on this project. This study is funded by the United States Department of Agriculture (USDA) and the West Virginia Agriculture and Forestry Experiment Stations, West Virginia University, College of Agriculture, Forestry and Consumer Sciences.

Purpose(s) of the study. This study will be performed in my home or at the WIC site. I will meet privately with the research assistant. I will be interviewed to answer several lists of written questions. The questions will be related to how I eat during pregnancy, my food shopping practices, my maternal health, prenatal care, and a variety of questions that could have a positive or a negative impact on my baby's health. I will also be asked to take one blood test by a trained lab technician to determine the level of certain nutrients in my blood. The quantity of blood to be taken from me for the one time blood draw will be about one tablespoon. Additionally, I will be asked to provide my baby's birth certificate. I do not have to answer all of the questions or provide any of the information from my prenatal records or my baby's birth certificate or take a blood test. I understand that it will take me about two hours to answer the interview questions and about ten minutes for the blood test. I will be given the opportunity to examine these questionnaires and handouts.

Risks. I understand that I may experience slight discomfort, bruising or bleeding during the one time blood draw by the trained technician. Some questions are of a sensitive nature, e.g. illicit drug use, hence I may feel uncomfortable when responding to these questions.

Benefits. I understand that there will be no direct benefit to me but what they learn from this study may help pregnant women and infants in West Virginia and other states.

Financial Considerations. If I join the study during my last trimester of pregnancy I understand that I will receive $\$ 35$ in cash after I complete the study. If I join the study when I am in my first or second trimester of pregnancy I will receive \$50 in cash after I complete the study. 
Division of Family and Consumer Sciences

\section{West Virginia University}

College of Agriculture, Forestry and Consumer Sciences

Contact Persons. For more information about this research, I can contact

at or her supervisor, Dr. Hazel Bourne Hiza at 304-293-3402 ext. 1768. For

information regarding my child's rights as a research subject, I may contact the Executive Secretary of the Institutional Review Board at 304-293-7073.

Confidentiality. I understand that any information obtained as a result of my participation in this research will be keptas legally possible. I understand that these research records will just like hospital records, may be subpoenaed by court order or may be inspected by federal regulatory authorities. However, I also know that such an occurrence is highly unlikely given the nature of this research. If any publications result from this research, neither my name nor any information from which I might be identified will be published.

Voluntary Participation. Participation in this study is voluntary. I understand that I may withdraw from this study at any time. Refusal to participate or withdraw will involve no penalty or loss of medical benefits or negative consequences for me. I have been given the opportunity to ask questions about the research, and I have received answers concerning areas I do not understand. Upon signing this form, I will receive a copy.

I willing consent to participate in this study.

Signature of Parent or Guardian

Signature of Investigator or

Investigator's Representative
Date

Date 
Division of Family and Consumer Sciences

West Virginia University

College of Agriculture, Forestry and Consumer Sciences

\title{
PARENTAL OR GUARIAN CONSENT FORM
}

\author{
Factors Affecting Perinatal, Maternal, \\ Nutritional Status, Healthcare and Pregnancy Outcomes
}

Introduction. I have been asked to allow my adolescent to participate in this study being conducted by Dr. Hazel Bourne Hiza and Dr. Virgil Norton at West Virginia University. This study is funded by the United States Department of Agriculture (USDA) and the West Virginia Agriculture and Forestry Experiment Stations, West Virginia University, College of Agriculture, Forestry and Consumer Sciences.

Purpose(s) of the study. This study will be performed in my home or at the WIC site. My adolescent will meet privately with the research assistant. She will be interviewed to answer several lists of written questions. The questions will be related to how she eats during pregnancy, her food shopping practices, her maternal health, prenatal care, and a variety of questions that could have a positive or negative impact on her baby's health. She will be asked to take one blood test by a trained lab technician to determine the level of certain nutrients in her blood. The quantity of blood to be taken from my daughter for the one time blood draw will be about one tablespoon. Additionally, my adolescent will be asked to provide her personal prenatal records and her baby's birth certificate. She does not have to answer any of the questions or provide any of the information from her prenatal records or her baby's birth certificate or take a blood test. I understand that it will take her about two hours to answer the interview questions and about ten minutes for the blood test. I will be given the opportunity to examine these questionnaires and handouts. I agree not to examine my adolescent's responses to the questions to protect her right of confidentiality.

Risks. I understand that my adolescent may experience slight discomfort, bruising or bleeding during the one time blood draw by the trained lab technician. Some questions are of a sensitive nature, e.g. illicit drug use, hence she may feel uncomfortable when responding to these questions.

Benefits. I understand that there will be no direct benefit to me but what they learn from this study may help pregnant women and infants in West Virginia and other states.

304-293-3402 FAX 293-2750 702 Allen Hall P.O. Box 6124 Morgantown, WV 26506-6124

Equal Opportunity / Affirmative Action Institution 
Division of Family and Consumer Sciences

\section{West Virginia University}

College of Agriculture, Forestry and Consumer Sciences

Financial Considerations. If she join the study during her last trimester of pregnancy I understand that my adolescent will receive $\$ 35$ in cash after she had completed the study. If she join the study in her first or second trimester of pregnancy she will receive $\$ 50$ in cash after she has completed the study.

Contact Persons. For more information about this research, I can contact at___ or her supervisor, Dr. Hazel Bourne Hiza at 304-293-3402 ext. 1768. For information regarding my child's rights as a research subject, I may contact the Executive Secretary of the Institutional Review Board at 304-293-7073.

Confidentiality. I understand that any information obtained as a result of my adolescent's participation in this research will be keptas legally possible. I understand that these research records will just like hospital records, may be subpoenaed by court order or may be inspected by federal regulatory authorities. However, I also know that such an occurrence is highly unlikely given the nature of this research. If any publications result from this research, neither my name nor that of my adolescent nor any information from which we might be identified will be published.

Voluntary Participation. Participation in this study is voluntary. I understand that I may withdraw my adolescent from this study at any time. Refusal to participate or withdraw will involve no penalty or loss of medical benefits or negative consequences for adolescent or me. I have been given the opportunity to ask questions about the research, and I have received answers concerning areas I do not understand. Upon signing this form, I will receive a copy.

I willing consent to participate in this study.

Signature of Parent or Guardian

Date

Signature of Investigator or

Date

Investigator's Representative 


\section{Vita}

Cortney Robyn Usakewicz

\section{Education:}

University of Connecticut, Storrs, CT

Bachelor of Science in Nutritional Science, May 1998

West Virginia University, Morgantown, WV

Master of Science in Nutrition, May 2000

\section{Professional Experience:}

June 1999-February 2000

AP4 Dietetic Intern

West Virginia University, Morgantown, WV

Food Service Rotation was through university facilities

Clinical Rotation was at Health South Mountainview Rehabilitation Hospital, Morgantown, WV

Community Rotation was completed at various surroundings in Monongalia County

August 1998-May 1999

Graduate Teaching Assistant

West Virginia University, Morgantown, WV

Major responsibilities included assisting in lab preparation, supervision of lab activities, class preparation, and grading 